will enable the reader to judge of the state of the work generally :-

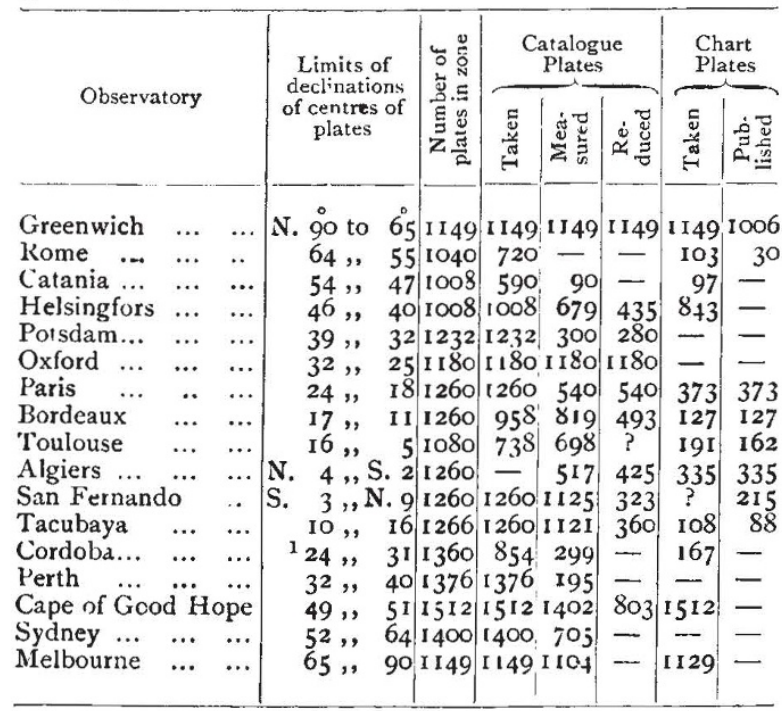

There was throughout the meeting an earnestness of purpose of a very marked kind, a feeling that decisions having an important influence on the future of astronomy were being taken. Every resolution had been so fully discussed in one or other of the five commissions that in the end they were all adopted with unanimity, not only in the commissions, but at the general conference.

Perhaps the most important of these are the resolutions dealing with the methods to be adopted in connection with the organisation of a united series of meridian observations, and the establishment by international effort of a system of intermediate stars, as originally suggested by Sir David Gill in his presidential address to the British Association at Leicester. Hardly less important are the resolutions in regard to the adjustment of the scale of photographic magnitudes to an absolute and uniform system for the whole sky. Indeed, it is hardly possible to overestimate the resulting importance of these resolutions to sidereal astronomy if due effect is given to these resolutions.

The plans for the observation of Eros show a still further extension of the work of the committee, for they carry us into another field of astronomy by providing the most refined determinations of the positions of that remarkable planet. If due effect is given to these resolutions, the gravitational astronomer will be provided with means of research on the masses of the moon and of the earth and other planets of a kind never before available. The meeting will also be memorable for the communication made to it by Mr. Hinks as to the result of his eight years of labour in deriving the solar parallax from the international observations of Eros.

Widely indeed has the permanent committee of the Astrographic Congress of 1887 extended the field of its labours, and with the best results.

Paris was, as usual, profuse in kindly hospitality. Prince Roland Bonaparte gave a reception to the members of the conference and their wives and families at his charming house in the Avenue d'Iéna. On the Thursday Baron Rothschild entertained some of the members to dinner, and on the same evening there was a delightful reception at the Paris Observatory, at which was given a little comedy by members of the Théâtre Français, and a little operetta by members of the Opéra Comique, the evening concluding with a tour de valse.

Many private entertainments to members were given at the hospitable homes of the Paris members of the conference, and the whole concluded with $a$ banquet at the observatory on the Saturday evening, at which covers were laid for eighty-two guests.

1 The zones $-17^{\circ}$ to $-23^{\circ}$ were originally allotted to La Plata, but as the work has not been done, thev are assigned, if rot entirely, at leact in chief part, to Santiago and the new observatory of Hyderahad (Deccan).
THE AMERICAN PHILOSOPHICAL SOCIETY. THE general meeting of the American Philosophical Society was held on April 22, 23, and 24. The evening of Friday, April 23, was devoted to a Darwin celebration commemorative of the centenary of Charles Darwin's birth and of the fiftieth anniversary of the publication of the "Origin of Species," at which addresses were given by the Right Hon. James Bryce, the British Ambassador; on personal reminiscences of Darwin and of the reception of the "Origin of Species"; by Prof. G. L. Goodale, of Harvard University, on the influence of Darwin on natural science; and by Prof. G. S. Fullerton, of Columbia University, on the influence of Darwin on the mental and moral sciences.

On the afternoon of April 24 there was a symposium on earthquakes, at which papers were presented by Prof. E. O. Hovey, Prof. W. H. Hobbs, and Prof. H. F. Reid. In addition to the three papers presented at the Darwin celebration on April 23, forty-four papers were read at the morning and afternoon sessions. We have been favoured with a list of these papers and summaries of their contents, but limitations of space prevent us from giving more than an abridged statement of the proceedings. Abstracts of a few of the papers read are subjoined.

The brains of two white philosophers and of two obscure negroes, Prof. B. G. Wilder. The brains of Chauncey Wright and of James Edward Oliver were compared with the brains of two obscure negroes, one a mulatto, the other black, and a remarkable resemblance in the form of Wright's brain with that of the negro brains was pointed out, from which Prof. Wilder drew the inference that the negro is capable of as high development as the Caucasian. Some conditions modifying the interpretation of human brain-weight records, Dr. H. H. Donaldson. An account of the brain-weight records that have been collected at the Wistar Institute of Anatomy. After the fiftenth year, up to the fifty-fifth, the human brain loses slightly in weight, and then more rapidly after that period. This slight loss in weight between the fifteenth and fiftyfifth years is attributed to the influence of those diseases which ultimately end in death.

Some notes on the modifications of colour in plants, Prof. H. Kraemer. After reviewing the previous work on the control of colour in plants, and enumerating the factors which influence the colour in flowers, the author gave the results of his own experiments, which were begun in the autumn of 1904, and have been continued up to the present time. Various soils were experimented with, including an artificial soil, and sand to which a special nutrient was added. The chemicals used to modify the colour principles were supplied to the plants in the form of solutions of varying strength, or added to the soil in the solid form, solution gradually taking place. Probably the most striking result obtained by the use of chemicals was the production of a red colour in the petals of the white rose, Kaiserine. The red pigment occurred in the basal portion of the petals, and was produced in the flowers of plants which were supplied with potassium hydrate, potassium carbonate, calcium hydrate, and lead acetate. Blue flowers were produced by the red-flowering form Hydrangea $(H$. Otaksa), growing in both sand and garden soil, when supplied with potassium and aluminium sulphate, aluminium sulphate and calcium hydrate.

Recent work on the physics of the æther, P. R. Heyl. Considerable interest has been taken of late in the question as to whether the æther is or is not a dispersive medium with regard to light. The work of the author, published about a year and a half ago, leads to the conclusion that any dispersion in the æther must be less than I part in 250,000 . Since that time others have arrived at the conclusion that there exists a dispersive effect of much smaller magnitude, about one part in a million. There seems to be no doubt of the correctness of their observations, but it is not clear that it is to be attributed to a real dispersive effect in the æther. It is more likely that it is due to tidal phenomena in the atmosphere of the variable stars used as sources of light in the experiments.

The detonation of gun-cotton, Prof. C. E. Munroe. In the use of gun-cotton in mines and torpedoes advantage is taken of the discovery of Mr. E. O. Brown that gun-

No. 2067 , vOL. 8o] 
cotton which is completely saturated with water may be detonated by the detonation of dry gun-cotton in direct contact with it used as a "priming charge," thus securing a large margin of safety for the naval vessels carrying the explosive. Wet gun-cotton containing as high as 35 per cent. of water has been shown to be a more efficient rupturing and shattering explosive than dry gun-cotton, but the question of how much water the discs of priming gun-cotton could contain to be efficient was the object of the research detailed in this paper. The primer was in all cases fired by the service detonator, containing 36 grains of mercuric fulminate. The results show that detonation of the entire charge was effected in every case in which the primer contained less than 12 per cent. of moisture, and occasionally was complete in cases where the moisture ran as high as 15 per cent., and therefore that such guncotton primers containing not more than 12 per cent. of moisture, fired by means of a detonator containing 35 grains of mercuric fulminate, may be relied upon to detonate wet gun-cotton with which they are in contact.

South American fossil Cetacea, Dr. F. W. True. Dr. True remarked that, in connection with a revision of the fossil whales and porpoises of the United States, he had had occasion to examine various specimens from Patagonia. Some of the Patagonian forms belong to families still represented in South America by living species. Others represent families no longer existing. The fossil fauna includes sperm whales, various forms allied to the Inia, others allied to Squalodon, and at least one species of whalebone whales, allied to the finbacks, but no ziphioid, or beaked, whales, nor any true dolphins, have been found.

On the remarkable changes in the tail of comet $c 1908$ (Morehouse), and on a theory to account for these changes, Prof. E. E. Barnard. The changes that occurred in the tail of this comet appear to indicate resistance to the passage of the body through space. In the discussion of the paper it was suggested that this resistance might arise from clouds of meteoric dust, too fine to be visibly appreciable, but still dense enough to offer a resistance that would account for the changes in the form of the tail of the comet.

On the ruling of diffraction gratings, Prof. A. A. Michelson. The paper gave a brief statement of the development of the grating. From the point of view of resolving power, the important fact is not so much the number of rulings per inch as the total number of rulings, and this greater number of rulings necessitates a correspondingly greater degree of regularity, an accumulated error of one ruling in the entire number being fatal. The ruling engine now set up in the Ryerson Laboratory gives this necessary increase in perfection of ruling, so that the spectra are almost free from ghosts, and those of the higher orders can be used. The resolving power is proportional to the product of the total number of rulings into the order. A photograph of a part of the mercury spectrum was shown, in which the distance between two of the lines was only $r / 200$ of the distance between the sodium (D) lines, and it was evident that lines separated by only half this distance would be distinctly resolved. This ruling engine is the result of seven years' work. The large ro-inch gratings are ruled on metal, to save the cutting edge of the diamond, and weigh about $30 \mathrm{lb}$. The greater part of this weight is supported by a float in mercury, only a small part pressing upon the ways. It is moved along the ways by a screw with a large head working by fine teeth in an automatically actuated worm. This screw was made as perfect as possible by long, careful grinding, and the remaining errors, which are of the order of the onemillionth part of an inch, are automatically compensated for by the slight tangential motion of the worm. This motion is a function of the position of the nut, determined empirically.

Solar activity and terrestrial magnetic disturbances, Dr. L. A. Bauer. This paper deals with the connections between the various manifestations of solar activity, e.g. sun-spots and the so-called magnetic storms which at times affect compass needles simultaneously all over the earth by several degrees, and even cause serious interruption in telegraph and cable lines, and are usually accc.npanied by fine auroral displays. One of the most important of the conclusions arrived at is that an increase in sun-spot activity is accompanied by a decrease in the earth's magnetisation, or that the magnetisation superposed on the earth's magnetic field during solar outbreaks is opposite to that of the earth's own tield. It appears questionable whether the earth's magnetism ever settles down precisely to its former condition after the occurrence of a magnetic storm. The facts are not yet sufficient to draw a definite conclusion whether solar activity and magnetic storms stand to each other as cause and effect, or whether they are both effects of the same cause. The indications are that during a period of intense solar activity, in some as yet unknown manner, considerable fluctuations are caused to take place in the electric field that we know from various facts exists in the regions above us. These varying electric currents in turn affect the magnetic needles on the earth's surface.

On the Hevelian halo, Prof. C. S. Hastings. The paper reviewed the various kinds of halos that have been described and the explanations that have been offered in regard to their origin. It had been assumed by writers on the subject that the snow crystals, which are in the form of plates or prisms, would fall with the plate or prism presenting the least resistance to the air. Thus, according to this idea, the hexagonal plates would fall edge on and the prism end on. This was shown to be incorrect, and the contrary was the case; the plates and prisms could fall through the air with their longer dimensions horizontal. The plates would assume a horizontal position as well as the prisms. The halo was then caused by total internal reflection from the plates or prisms, and not by surface reflection. Assuming these general positions for the long or short prisms (or plates) and total internal reflection, the various types of halo that have been described could be explained, with the exception of the Hevelian halo. To explain this on the basis of total internal reflection, it was necessary to assume pyramidal planes in the crystal of such an angle as to produce the 9o-degree halo of this rare type.

The effect of temperature on the absorption of certain solutions, Prof. H. C. Jones. Increase of temperature of the solution was found to alter the absorption spectra in the same way that they are changed by concentration of the solution.

Symposium on earthquakes, Prof. E. O. Hovey, Prof. W. H. Hobbs, and Prof. H. F. Reid. Prof. Hovey's paper served as an introduction to the subject. The ideas in regard to the cause of earthquakes were considered, especial attention being given to a discussion of volcanic earthquakes. Prof. Hobbs pointed out the fact that the seismic focus or centrum, as determined by the method of Mallet, was at best a line, and practically had no existence. He explained the production of earthquakes by the shifting of segments of the crust along already existing fissures, and insisted upon the tectonic origin of earthquakes. Prof. H. F. Reid considered three phases of the subject:- $(a)$ conditions leading to tectonic earthquakes; $(b)$ instruments used in the study of earthquakes; (c) suggestions for a national seismological bureau.

The burning bush and the origin of Judaism, Prof. F. Haupt. The burning bush was explained as the shrubbery on the heights of a volcano, lighted up at night by the glow of the incandescent lava. The story of the pilla of cloud by day and the pillar of fire by night was no that it hung over the Tabernacle, but over Mount Sinai the cloud of steam from the active volcano was the " "pillar of cloud by day and the pillar of fire by night." The destruction of Jericho and of Sodom and Gomorrah were attributed to earthquakes.

At the Darwin commemoration meeting, after the presentation of the three addresses, attention was directed to the fact that there are two members of the American Philosophical Society still living in England who were friends of Charles Darwin, Sir Joseph Dalton Hooker and Dr. Alfred Russel Wallace. It was unanimously resolved that the society should cable to them its greetings and congratulations on the general, acceptance of the views in the elaboration and promulgation of which they had taken such an effective part.

The following resolutions were adopted in the course of the meeting:- $(\mathrm{r})$ Whereas the United States in former 
years made many brilliant discoveries in the Antarctic, including the continent of Antarctica by Charles Wilkes, and whereas the United States have not taken any part in the recent scientific explorations of the South Polar region, therefore be it fesolved that the American Philosophical Society requests the cooperation of the scientific and geographical societies of the United States, to urge on the navy of the United States and through the general Government, that it do make sufficient appropriations to fit a Government vessel thoroughly to explore and survey the coast of Wilkes Land and other parts of Antarctica.

(2) Whereas earthquakes have been the cause of great loss of life and property within the territory of the United States and its possessions, as well as other countries, and whereas it is only through the scientific investigation of the phenomena that there is hope of discovering the laws which govern them, so as to predict their occurrences and to reduce the danger to life and property, and whereas such investigations can be successfully conducted only with the support of the general Government, be it therefore resolved that this society urges upon Congress the establishment of a national bureau of seismology, and suggests that this bureau be organised under the Smithsonian Institution with the active cooperation of the other scientific departments of the Government, and that this bureau be charged with the following duties:- $(a)$ the collection of seismological data; $(b)$ the establishment of observing stations ; (c) the organisation of an expeditionary corps for the investigation of special earthquakes and volcanic eruptions in any part of the world; $(d)$ the study and investigation of special earthquake regions within the national domain.

The annual election of members, held at the executive session on April 24, resulted in the election of the following candidates:-Residents of the United States: L. A. Bauer, M. T. Bogert, H. C. Bumpus, A. Carrel, E. B. Frost, R. A. Harper, W. H. Hobbs, A. V. W. Jackson, J. F. Lewis, A, L. Lowell, W. R. Newbold, C. B. Penrose, W. H. Taft, C. R. Van Hise, V. C. Vaughan. Foreign residents: Francis Darwin, H. Diels, E. Fischer, F. Kohlrausch, W. F. P. Ofeffer.

\section{THE ITALIAN EARTHQUAKE} OF DECEMBER 28, i908.

A PRELIMINARY account, based on material collected for the official report, on the Calabrian earthquake of December 28,1908 , by $\mathrm{Dr}$. G. Martinelli, is published in the last issue of the Bolletino Bimensuale of the Italian Meteorological Society. The earthquake was felt, not only over the whole of Sicily and of Italy south of Naples and Campobasso, but also in Montenegro, the coastal districts of Albania, and in the islands of Zante, Corfu, and Cephaionia. The greatest violence was experienced in the neighbourhood of the Straits of Messina, but there were also two independent centres in Sicily, one near Raddusa and the other near Augusta, in which the violence reached seven and eight degrees of the Mercalli scale respectively. The epoch of the shock was 5 h. $20 \mathrm{~m} .23 \mathrm{~s}$., and its duration about 30 . to 40 . ; outside the central area it attained 5os. at Capo d'Armi, Capo Spartivento, Palmi, \&c., and as much as 6os. at Cataforio, but at greater distances the duration became less, being only 20 s. to $25 \mathrm{~s}$. at Naples. The character of the shock is described as undulatory, perpendicular, and rotary or vorticose in the central district, but the vorticose movement was not noticed where the shock fell below the eighth degree of the Mercalli scale, or a destructive degree of violence.

NO. 2067 , VOL. 8o]
The disturbance of the sea produced by the earthquake was greatest along the opposite coasts of Italy and Sicily, and much greater to the south than to the north of the Straits of Messina. It was noticed all along the northern coast of Sicily as far westwards as Termini, but on the Italian coast the only record is from Vibonati, where the sea is said to have been agitated for a short time, and it is expressly stated that no sea wave was noticed at Bagnara, Scilla, or anywhere north of Cannitelio, which is situated at the entrance to the straits. The marine effects of the earthquake form the special subject of a note by Prof. G. Platania in the Rivista Geografica Itaiiana (vol. xv., I909, p. 644), who gives some particulars not mentioned by Dr. Martinelli. The first effect everywhere was a retreat of the sea, and then the advance of a great wave, followed by two or three others of decreasing amplitude, except at Catania and Giampileri, where the second is said to have been greater than the first. The height of the wave, as shown by the marks left on buildings, was $2.70 \mathrm{~m}$. at Messina, but considcrably higher at other places, the greatest rise measured being $8.40 \mathrm{~m}$. at Giardini and $\mathrm{Ali}$, and $8.50 \mathrm{~m}$. 